\title{
Desempenho, características da carcaça, digestibilidade aparente dos nutrientes, metabolismo de nitrogênio e parâmetros ruminais de cordeiros alimentados com rações contendo polpa cítrica úmida semidespectinada elou polpa cítrica desidratada
}

\author{
Gustavo Henrique Rodrigues ${ }^{1}$, Ivanete Susin ${ }^{2}$, Alexandre Vaz Pires ${ }^{2}$, Luiz Gustavo \\ Nussio ${ }^{2}$, Renato Shinkai Gentil ${ }^{1}$, Evandro Maia Ferreira ${ }^{1}$, Marcos Vinicius Biehl ${ }^{1}$, \\ Michele Ferreira Ribeiro ${ }^{3}$
}

\footnotetext{
1 Pós-graduação em Ciência Animal e Pastagens - ESALQ/USP - Piracicaba, SP.

2 Departamento de Zootecnia - ESALQ/USP - Piracicaba, SP

${ }^{3}$ Graduação em Engenharia Agronômica - ESALQ/USP - Piracicaba, SP.
}

RESUMO - O objetivo neste estudo foi avaliar os efeitos da substituição parcial da polpa cítrica desidratada (PCD) pela polpa cítrica úmida semidespectinada in natura (PCUD), silagem de polpa cítrica úmida semidespectinada (PCUDS) ou silagem de polpa cítrica úmida semidespectinada adicionada de benzoato de sódio (PCUDS+B) sobre o desempenho, as características da carcaça, a digestibilidade aparente dos nutrientes, os parâmetros ruminais e o metabolismo de nitrogênio. Na avaliação de desempenho, 64 cordeiros Santa Inês foram alimentados com rações contendo 95\% de concentrado e 5\% de bagaço de canade-açúcar in natura durante 56 dias. O delineamento experimental utilizado foi o de blocos completos casualizados (BCC). A dieta controle continha 69,5\% de PCD e foi substituída em 30\% na matéria seca (MS) pela PCUD, PCUDS ou PCUDS+B. Não houve diferença no consumo de MS, no ganho médio diário de peso e nas características das carcaças. No entanto, a eficiência alimentar dos cordeiros alimentados com PCUD foi maior que a daqueles alimentados com PCD. No ensaio de metabolismo, 16 borregos Santa Inês, canulados no rúmen, foram distribuídos em BCC e alimentados com rações contendo 85\% de concentrado e $15 \%$ de bagaço de cana-de-açúcar in natura. A dieta controle continha 75,3\% de PCD e foi substituída em 30\% na MS pela PCUD, PCUDS ou PCUDS+B. Não houve diferença nos coeficientes de digestibilidade da MS, matéria orgânica e proteína bruta. O coeficiente de digestibilidade da fibra em detergente neutro, porém foi maior para a PCUD comparado à PCD. A concentração de amônia no fluido ruminal foi maior para as rações contendo PCD em comparação àquelas com PCUDS e PCUDS+B. No entanto, para os demais parâmetros ruminais não foi verificado efeito dos tratamentos. A PCUD in natura ou ensilada pode substituir parcialmente a PCD em rações com alta proporção de concentrado para cordeiros em confinamento.

Palavras-chave: confinamento, coprodutos, pectina, Santa Inês, silagem

\section{Performance, carcass characteristics, apparent digestibility of nutrients, nitrogen metabolism and ruminal measures of lambs fed diets containing wet low pectin citrus pulp and/or dried citrus pulp}

\footnotetext{
ABSTRACT - The objective of this study was to determine the effects of partial replacement of dried citrus pulp (DCP) by wet low pectin citrus pulp (WLPCP), wet low pectin citrus pulp silage (WLPCPS) or wet low pectin citrus pulp silage with sodium benzoate (WLPCPS+B) on performance and carcass characteristics, apparent digestibility of nutrients, ruminal measures, and nitrogen metabolism of lambs. In the performance trial, 64 Santa Inês ram lambs were fed 95\% concentrate and $5 \%$ sugarcane bagasse diets during 56 days. The experimental design was a randomized complete block (RCB). The control diet contained 69.5\% DCP, while in the other treatments fresh or ensiled WLPCP replaced DCP by 30\% on a DM basis. There were no differences in DMI, ADG or carcass characteristics. However, feed efficiency was greater for lambs fed WLPCP compared with lambs fed DCP. In the digestibility trial, 16 Santa Inês ram lambs, canulated in the rumen, were assigned to a RCB design. Animals were fed diets containing $85 \%$ of concentrate and $15 \%$ of sugarcane bagasse. The control diet contained $75.3 \%$ DCP. A portion (30\%) of the DCP DM was replaced by WLPCP, WLPCPS or WLPCPS+B. There was no difference in DM, organic matter or crude protein apparent digestibilities, except for neutral detergent fiber digestibility. Additionally, ruminal ammonia concentration was higher in diets containing DCP compared with WLPCPS and WLPCPS+B. Nevertheless, no effects of treatments were seen on the other ruminal measures. Fresh or ensiled WLPCP can partially replace DCP in rations with high level of concentrate for feedlot lambs.
}

Key Words: byproducts, feedlot, pectin, Santa Ines, silage 


\section{Introdução}

A demanda por carne de cordeiro é notada nos grandes centros consumidores do País, principalmente por ser diferente das carnes tradicionais. Entretanto, apesar do grande potencial de crescimento do setor, evidenciado pelo fato de a maior parte dessa carne ser importada da Argentina, do Uruguai e da Nova Zelândia, sua oferta ainda é sazonal e incipiente. Uma forma de amenizar esses entraves e atender o mercado é usar sistemas intensivos de produção. Particularmente no estado de São Paulo, essa prática pode ser justificada pelo preço elevado da terra e pelas reduzidas áreas de pastagens, que ainda competem com outras culturas.

A rentabilidade de sistemas intensivos de produção de cordeiros está diretamente ligada ao custo e à qualidade dos ingredientes utilizados na formulação das rações. O aproveitamento de resíduos agroindustriais na alimentação animal tem por objetivo reduzir o custo de produção e, em muitos casos, evitar danos ao meio ambiente. Tendo como característica o seu excelente valor nutricional e a sua produção coincidindo com a entressafra de grãos e a escassez de forragens, o resíduo da indústria citrícola é um exemplo de que a utilização de fontes alimentares alternativas energéticas pode viabilizar sistemas intensivos de produção.

A extração de pectina a partir do resíduo de citros obtido da indústria processadora de suco resulta na polpa cítrica úmida semidespectinada. Este produto tem custo inferior se comparado ao produto desidratado justamente por não ser submetido ao oneroso processo de secagem. Outro importante aspecto favorável à utilização deste coproduto é a possibilidade de conservá-lo na forma de silagem, o que torna atraente sua aquisição. No entanto, sabe-se que a pectina apresenta alto valor energético para animais ruminantes e que é o principal carboidrato responsável pelo sucesso na utilização de polpa cítrica desidratada como ingrediente energético. Diante disso, torna-se importante estudar os impactos que a redução na concentração de pectina na polpa cítrica pode causar em seu valor alimentício para animais ruminantes. Além disso, não existem estudos envolvendo a utilização desse subproduto como fonte energética em rações com altos teores de concentrado para cordeiros em confinamento.

Desse modo, objetivou-se com este estudo avaliar os efeitos da inclusão da polpa cítrica úmida semidespectinada in natura ou ensilada em substituição parcial à polpa cítrica desidratada em rações contendo alto teor de concentrado sobre o desempenho, as características da carcaça, a digestibilidade aparente dos nutrientes, os parâmetros ruminais e o metabolismo de nitrogênio de cordeiros confinados.

\section{Material e Métodos}

Os experimentos foram conduzidos no Sistema Intensivo de Produção de Ovinos e Caprinos (SIPOC) do Departamento de Zootecnia da Escola Superior de Agricultura “Luiz de Queiroz” (ESALQ), Universidade de São Paulo.

No experimento 1, foram utilizados 64 cordeiros machos da raça Santa Inês com peso inicial médio de 17 $( \pm 2) \mathrm{kg}$ e idade inicial média de $75( \pm 5)$ dias. Os animais foram confinados em baias cobertas com piso de concreto, cocho e bebedouros e distribuídos dois animais por baia e oito baias por tratamento. Todos os animais foram vacinados contra clostridioses e receberam aplicação de suplemento vitamínico ADE antes do início do experimento.

O período experimental teve duração de 56 dias. Os animais foram pesados em balança eletrônica da marca Marte ${ }^{\circledR}$, modelo LC 100, com precisão de 20 g, nos dias 0 e 56 do período experimental após jejum alimentar de 16 horas. Os tratamentos foram definidos pela substituição de $30 \%$ da polpa de citros desidratada (PCD) pela polpa de citros úmida semidespectinada (PCUD) in natura, a silagem de PCUD (PCUDS) ou a PCUDS com adição de benzoato de sódio (PCUDS+B). As rações foram formuladas para serem isonitrogenadas $(16,4 \pm 0,5 \% \mathrm{~PB})$ e constituídas de $5 \%$ de volumoso (bagaço de cana-de-açúcar in natura) e $95 \%$ de concentrado (\% da MS) (Tabela 1).

Tabela 1- Proporção dos ingredientes e composição química das rações experimentais (\% na MS) do experimento de desempenho

\begin{tabular}{|c|c|c|c|c|}
\hline \multirow[t]{2}{*}{ Ingrediente } & \multicolumn{4}{|c|}{ Tratamento $^{1}$} \\
\hline & PCD & PCUD & PCUDS & PCUDS+B \\
\hline Bagaço de cana in natura & 5,0 & 5,0 & 5,0 & 5,0 \\
\hline PCD & 69,5 & 47,7 & 47,7 & 47,7 \\
\hline PCUD & - & 20,3 & - & - \\
\hline PCUDS & - & - & 20,3 & - \\
\hline PCUDS+B & - & - & - & 20,3 \\
\hline Farelo de algodão & 22,9 & 24,4 & 24,4 & 24,4 \\
\hline Ureia & 0,5 & 0,5 & 0,5 & 0,5 \\
\hline Sal mineral ${ }^{2}$ & 1,6 & 1,6 & 1,6 & 1,6 \\
\hline Cloreto de amônio & 0,5 & 0,5 & 0,5 & 0,5 \\
\hline \multicolumn{5}{|l|}{ Composição química } \\
\hline Matéria seca & 86,3 & 46,1 & 43,8 & 44,1 \\
\hline Matéria mineral & 7,3 & 3,6 & 3,8 & 3,9 \\
\hline Matéria orgânica & 92,7 & 96,4 & 96,2 & 96,1 \\
\hline Proteína bruta & 17,1 & 16,2 & 15,9 & 16,4 \\
\hline Fibra em detergente neutro & 28,7 & 50,1 & 53,1 & 53,9 \\
\hline Extrato etéreo & 2,1 & 3,8 & 2,1 & 2,7 \\
\hline \multicolumn{5}{|c|}{$\begin{array}{l}{ }^{1} \text { Tratamentos: PCD = polpa cítrica desidratada; PCUD = polpa cítrica úmida } \\
\text { semidespectinada; PCUDS = polpa cítrica úmida semidespectinada ensilada; } \\
\text { PCUDS+B = polpa cítrica úmida semidespectinada ensilada com a adição de } \\
\text { benzoato de sódio. } \\
{ }^{2} \text { Composição: fósforo - 7,5\%; cálcio - 13,4\%; magnésio - } 1 \% \text {; enxofre - } 7 \% \text {; sódio - } \\
\text { 14,5\%; cloro - } 21,8 \% \text {; ferro - } 500 \mathrm{ppm} \text {; cobre - } 300 \mathrm{ppm} \text {; zinco - } 4.600 \mathrm{ppm} \text {; } \\
\text { manganês - } 1100 \text { ppm; iodo - } 55 \text { ppm; cobalto - } 40 \mathrm{ppm} \text {; selênio - } 30 \mathrm{ppm} \text {. }\end{array}$} \\
\hline
\end{tabular}

R. Bras. Zootec., v.40, n.10, p.2252-2261, 2011 
A PCUD foi fornecida pela CPkelco S.A. (Limeira - SP) em duas remessas, uma no início do ensaio de desempenho e outra no início do ensaio de digestibilidade. O subproduto in natura foi acondicionado em tambores plásticos com capacidade de 200 litros. A PCUDS e PCUDS+B foram confeccionadas em janeiro de 2006 e começaram a ser utilizadas para a alimentação dos animais em janeiro de 2007. O benzoato de sódio utilizado na PCUDS+B foi aplicado na superfície da silagem na proporção de $0,18 \%$ da matéria verde.

Após o período de avaliação do desempenho, todos os animais foram abatidos quando atingiram o peso de abate pré-estabelecido (35 kg), após jejum de sólidos por 16 horas. $\mathrm{O}$ abate dos animais foi realizado segundo as normas descritas no Regulamento da Inspeção Industrial e Sanitária de Produtos de Origem Animal - RIISPOA (Brasil, 1997).

Uma hora após o abate, as carcaças foram pesadas individualmente em balança eletrônica da marca Marte ${ }^{\circledR}$, modelo LC 100, com precisão de 20 g, para obtenção do peso da carcaça quente, e refrigeradas a $2{ }^{\circ} \mathrm{C}$ por 24 horas. Passado este tempo, as carcaças foram novamente pesadas para obtenção do peso da carcaça resfriada. A perda por resfriamento foi calculada pela diferença entre o peso da carcaça quente e o peso da carcaça resfriada.

A espessura de gordura (EG) e a área de olho-de-lombo (AOL) foram medidas na meia-carcaça direita, de modo que a EG foi mensurada entre a $12^{\underline{a}}$ e $13^{\underline{a}}$ costela na parte posterior da meia-carcaça utilizando-se um paquímetro digital graduado em milímetros. A AOL foi desenhada no músculo exposto longissimus com papel-vegetal e posteriormente determinada por meio de um planímetro com resultado em $\mathrm{cm}^{2}$.

O delineamento experimental foi o de blocos completos casualizados com quatro tratamentos e oito repetições, sendo os blocos definidos pelo peso e idade dos animais no início do experimento. Os dados foram analisados pelo procedimento GLM do pacote estatístico SAS (2002). As médias foram obtidas pelo comando LSMEANS e comparadas pelo teste de Tukey, sendo as diferenças declaradas significativas quando $\mathrm{P}<0,05$.

Para determinação da digestibilidade aparente dos nutrientes, dos parâmetros ruminais e do metabolismo de nitrogênio, foram utilizados 16 borregos da raça Santa Inês, com peso inicial médio de 41,3 kg e idade média de oito meses distribuídos em delineamento experimental de blocos completos casualizados com 4 tratamentos e 4 repetições. Os animais foram alojados individualmente em gaiolas metálicas para ensaios de metabolismo com dimensões de $1,3 \times 0,55 \mathrm{~m}$, providas de cochos e bebedouros e sistema para separação de fezes e urina.
O período experimental teve duração de 15 dias, dos quais 10 dias foram destinados à adaptação dos animais às rações experimentais e às instalações, 4 dias para medição do consumo de ração e colheita de amostras das rações ofertadas, das sobras, fezes e urina e um dia (D15) para colheita das amostras do fluido ruminal. Os animais foram pesados no início e no final do período de colheita. Os tratamentos foram definidos pela substituição de 30\% da polpa de citros desidratada (PCD) pela polpa de citros úmida semidespectinada (PCUD) in natura, a silagem de PCUD (PCUDS) ou a PCUDS com adição de benzoato de sódio (PCUDS+B). As rações foram formuladas para serem isonitrogenadas $(15,6 \pm 0,9 \% \mathrm{~PB})$ e foram compostas de $15 \%$ de volumoso (bagaço de cana-de-açúcar in natura) e $85 \%$ de concentrado (\% da MS) (Tabela 2 ).

Todos os dias do período de colheita as rações foram pesadas em balança eletrônica com precisão de $5 \mathrm{~g}$ e ofertadas ad libitum às 7 horas da manhã. A quantidade de ração ofertada foi ajustada com base no consumo de ração obtido durante o período de adaptação dos animais, não sendo permitidas sobras superiores a $10 \%$ da quantidade ofertada.

Durante os primeiros quatro dias do período de colheita, às 7 horas, foram pesadas as sobras de ração, para a obtenção do consumo de matéria seca (CMS) por animal. No mesmo horário, diariamente, as fezes foram quantificadas. Para a colheita de fezes, foram utilizados arreios, que continham uma bolsa colhedora de fezes, com o objetivo de

Tabela 2 - Proporção dos ingredientes e composição química das rações experimentais (\% na MS) do experimento de digestibilidade

\begin{tabular}{|c|c|c|c|c|}
\hline \multirow[t]{2}{*}{ Ingrediente } & \multicolumn{4}{|c|}{ Tratamento $^{1}$} \\
\hline & PCD & PCUD & PCUDS & $\mathrm{PCUDS}+\mathrm{B}$ \\
\hline Bagaço de cana in natura & 15,1 & 15,1 & 15,1 & 15,1 \\
\hline PCD & 75,3 & 52,5 & 52,5 & 52,5 \\
\hline PCUD & - & 22,5 & - & - \\
\hline PCUDS & - & - & 22,5 & - \\
\hline PCUDS+B & - & - & - & 22,5 \\
\hline Farelo de algodão & 5,1 & 5,2 & 5,2 & 5,2 \\
\hline Ureia & 1,9 & 2,1 & 2,1 & 2,1 \\
\hline Sal mineral ${ }^{2}$ & 1,7 & 1,7 & 1,7 & 1,7 \\
\hline Bicarbonato de sódio & 0,9 & 0,9 & 0,9 & 0,9 \\
\hline \multicolumn{5}{|l|}{ Composição química } \\
\hline Matéria seca & 82,3 & 39,5 & 38,3 & 37,0 \\
\hline Matéria mineral & 8,8 & 7,5 & 7,6 & 7,1 \\
\hline Proteína bruta & 15,4 & 15,7 & 16,3 & 15,0 \\
\hline Fibra em detergente neutro & 39,1 & 45,4 & 47,5 & 47,9 \\
\hline \multicolumn{5}{|c|}{$\begin{array}{l}1 \text { Tratamentos: PCD = polpa cítrica desidratada; PCUD = polpa cítrica úmida } \\
\text { semidespectinada; PCUDS = polpa cítrica úmida semidespectinada ensilada; } \\
\text { PCUDS+B = polpa cítrica úmida semidespectinada ensilada com a adição de } \\
\text { benzoato de sódio. }\end{array}$} \\
\hline
\end{tabular}

R. Bras. Zootec., v.40, n.10, p.2252-2261, 2011 
evitar a mistura de fezes e urina. Amostras de $10 \%$ da ração ofertada, das sobras e das fezes foram colhidas, compostas por animal e armazenadas a $-20^{\circ} \mathrm{C}$.

As amostras de ração fornecida, sobras e ingredientes individuais da ração foram pré-secas em estufa com ventilação de ar forçada, regulada a $55^{\circ} \mathrm{C}$, pelo período de 72 horas (Campos et al., 2004). Em seguida, todas as amostras foram trituradas em moinho do tipo Wiley provido de peneira com crivos de $1 \mathrm{~mm}$ de diâmetro. A segunda matéria seca (MS) foi determinada em estufa a $105^{\circ} \mathrm{C}$ por 12 horas. As cinzas (MM) foram obtidas por meio da incineração das amostras em mufla à temperatura de $550{ }^{\circ} \mathrm{C}$ durante 3 horas (AOAC, 1990). A matéria orgânica (MO) foi calculada pela diferença entre a MS e a MM. O teor de fibra em detergente neutro (FDN) foi determinado com o uso de sulfito de sódio com a adição de enzima $\alpha$-amilase termoestável (Van Soest et al., 1991), com auxílio do analisador de fibra modelo ANKON Fiber Analyser (ANKON ${ }^{\circledR}$ Technology Corp.), descrito por Holden (1999). A concentração de FDN foi corrigida para cinzas.

A determinação de nitrogênio total das fezes e dos alimentos foi realizada com base na combustão das amostras pelo analisador da marca LECO ${ }^{\circledR}$ (Wiles et al., 1998), modelo FP-528 com temperatura para combustão de $835^{\circ} \mathrm{C}$. O teor de proteína bruta (PB) foi obtido por meio da multiplicação do teor de nitrogênio total por 6,25.

A urina dos animais foi colhida automaticamente pelos colhedores das gaiolas metabólicas em vasilhames que continham de 20 a $60 \mathrm{~mL}$ de ácido clorídrico 6 N. O volume de ácido era o suficiente para manter o $\mathrm{pH}$ da urina abaixo 3. Diariamente no mesmo horário da colheita das fezes, $10 \%$ do volume total de urina foram amostradas e congeladas a $-20^{\circ} \mathrm{C}$. Para determinação de nitrogênio as amostras foram descongeladas, compostas por animal e analisadas pelo método micro Kjeldahl, conforme descrito por Campos et al. (2004).

Amostras do fluido ruminal foram colhidas no último dia do período experimental (15으 dia), com intervalos de duas horas entre cada colheita. Os horários de colheita foram determinados com base no fornecimento da ração. A hora zero correspondeu ao momento antes do fornecimento da ração, sendo as demais colheitas realizadas 2, 4, 6, 8, 10 e 12 horas após o arraçoamento.

Uma amostra representativa do conteúdo ruminal de cada animal, foi colhida via cânula, sendo rapidamente filtrada em tecido de algodão, obtendo-se, aproximadamente $200 \mathrm{~mL}$ de fluido ruminal. Em seguida, foi realizada a mensuração imediata do $\mathrm{pH}$ em potenciômetro digital(DIGIMED ${ }^{\circledR}$ DM20) e a fase sólida do conteúdo ruminal que permaneceu no tecido após a filtragem, foi devolvida ao rúmen.
Após determinação do $\mathrm{pH}$, retiraram-se 2 alíquotas de $25 \mathrm{~mL}$ do fluido ruminal. As alíquotas foram armazenadas em frascos plásticos contendo 1,25 mL de ácido clorídrico, e congeladas a $-20{ }^{\circ} \mathrm{C}$ para análise de ácidos graxos de cadeia curta e nitrogênio amoniacal.

Para determinação do nitrogênio amoniacal $\left(\mathrm{N}-\mathrm{NH}_{3}\right)$, a amostra de líquido ruminal foi descongelada e centrifugada a $12.000 \times \mathrm{g}$ a $4{ }^{\circ} \mathrm{C}$ durante 20 minutos. A alíquota sobrenadante foi utilizada para a determinação, seguindo o método colorimétrico proposto por Chaney \& Marbach (1962), adaptado para a leitura em microplaca (Bio-Rad, Hercules, EUA), utilizando-se filtro para absorbância de 550 nm (Campos et al., 2004). A outra alíquota sobrenadante foi utilizada para a determinação da concentração dos ácidos graxos de cadeia curta (AGCC) em cromatógrafo líquido-gasoso, segundo Palmquist \& Conrad (1971). O equipamento utilizado foi um CLG (Hewlett Packard Company ${ }^{\circledR} 5890$ serie II), equipado com braço mecânico (HP integrator 3396 serie II, Hewlett Packard Company $\left.{ }^{\circledR}\right)$. As amostras foram previamente preparadas e armazenadas sob refrigeração $\left(-20{ }^{\circ} \mathrm{C}\right)$ em recipientes apropriados ao equipamento, contendo $800 \mu \mathrm{L}$ do extrato, $200 \mu \mathrm{L}$ de ácido fórmico e $100 \mu \mathrm{L}$ de padrão interno.

Os dados relativos ao ensaio de digestibilidade e balanço de nitrogênio foram analisados pelo procedimento PROC GLM do pacote estatístico SAS (2002). As médias foram obtidas pelo comando LSMEANS e comparadas pelo teste de Tukey, sendo as diferenças declaradas significativas quando $\mathrm{P}<0,05$. Os dados de parâmetros ruminais foram analisados como medidas repetidas no tempo (hora das medidas) pelo procedimento MIXED do pacote estatístico SAS (2002).

\section{Resultados e Discussão}

Não foi observado efeito $(P>0,05)$ da inclusão de PCUD in natura ou ensilada em substituição parcial a PCD sobre o ganho diário médio de peso (GDM), resultado que pode ser justficado pela ausência de efeito dos tratamentos ( $\mathrm{P}>0,05)$ sobre o consumo de matéria seca (CMS) e consumo de matéria orgânica (CMO), expresso em kg/dia ou em \% do PV (Tabela 3). Estes resultados têm suporte em pesquisas com a de Sarturi (2008), que forneceu dietas semelhantes às deste experimento para bovinos de corte e não verificaram efeito sobre o GDM. Conforme apresentado no experimento 2, a digestibilidade aparente da MS e MO não diferiu entre os tratamentos (Tabela 5), o que também justifica GDM semelhante entre as dietas.

As médias encontradas para o GDM e CMS foram de 221 e 889 g, respectivamente, resultados que estão de acordo 
com os comumente encontrados para cordeiros da raça Santa Inês alimentados com dietas contendo alto teor de concentrado (Urano et al., 2006; Queiroz et al., 2008). O GDM verificado foi ligeiramente superior ao reportado por Rodrigues et al. (2008a), que também avaliaram dietas com alto teor de concentrado ( $90 \%$ da MS) contendo PCD (68,4\% da MS) e observaram GDM de $167 \mathrm{~g}$, reforçando a ideia de que a PCUD in natura ou ensilada tem grande potencial como ingrediente energético na ração de cordeiros em terminação.

A oferta da dieta PCD resultou no maior $(\mathrm{P}<0,05)$ consumo de $\mathrm{PB}$ e não houve diferença $(\mathrm{P}>0,05)$ entre PCUD, PCUDS e PCUDS+B. A concentração de PB nas dietas experimentais foi semelhante entre os tratamentos, portanto, a diferença observada no consumo de proteína pode estar relacionada à seleção pelos animais (Tabela 1).

O consumo de FDN foi maior para os animais alimentados com PCUD in natura ou na forma de silagens em relação à PCD $(\mathrm{P}<0,05)$ (Tabela 3$)$, fato atribuído à maior concentração de FDN na polpa cítrica úmida semidespectinada (Tabela 1 ).

Os resultados comprovam que a FDN da PCUD na forma in natura ou ensilada apresenta baixa capacidade de enchimento ruminal, visto que, embora o consumo de FDN tenha aumentado com a substituição da PCD pela PCUD, esse maior consumo não ocasionou redução no consumo de MS. Essa ideia pode ser sustentada pela afirmação de Mertens (1992) de que o consumo de MS está negativamente correlacionado à concentração de FDN quando o enchimento ruminal limita a ingestão. Uma possível justificativa para essa resposta seria o fato de que a composição da FDN da PCUD tenha sido alterada durante o processamento, o que pode ter melhorado sua qualidade. Sarturi (2008), por exemplo, relatou que uma ração contendo PCD proporcionou maior tempo de ruminação e de mastigação por kg de FDN em comparação a uma ração contendo PCUD, mesmo considerando que a última continha maior teor de FDN (36,1 vs. 45,3\%). Esse efeito comprova que a FDN da PCUD apresenta baixa efetividade física.

Um fator que pode ter contribuído para o aumento no CFDN das rações contendo PCUD é o fato dela apresentar alta umidade (em média 44,7\% de MS), o que contribui para redução da seleção pelos animais, conforme sugerido por Leonardi et al. (2005).

As silagens de polpa cítrica úmida despectinada apresentaram variáveis bromatológicas semelhantes às encontradas na polpa cítrica úmida semidespectinada in natura nos dois experimentos (Tabelas 1 e 2). Esse fato confere a este subproduto características positivas quanto à capacidade de armazenamento na forma de silagem como verificado por Sarturi (2008).

Para completa avaliação do sistema de produção, as características da carcaça são consideradas informações complementares aos resultados de desempenho animal. Os animais foram abatidos com idade e peso semelhantes ( $P>0,05)$, o que deve ter contribuído para ausência de efeito $(\mathrm{P}>0,05)$ da substituição parcial da PCD pela PCUD sobre os demais parâmetros avaliados referentes às características da carcaça (Tabela 4).

Tabela 3 - Desempenho de cordeiros Santa Inês alimentados com rações contendo polpa cítrica úmida semidespectinada in natura, ensilada com ou sem benzoato em substituição parcial a polpa cítrica desidratada

\begin{tabular}{|c|c|c|c|c|c|c|}
\hline \multirow[t]{2}{*}{ Variáveis ${ }^{c}$} & \multicolumn{4}{|c|}{ Tratamento $^{\mathrm{d}}$} & \multirow[t]{2}{*}{$\mathrm{EPM}^{\mathrm{e}}$} & \multirow[t]{2}{*}{ Efeito $^{\mathrm{f}}$} \\
\hline & PCD & PCUD & PCUDS & PCUDS+B & & \\
\hline Peso inicial, kg & 17,6 & 16,9 & 17,0 & 17,1 & - & - \\
\hline Peso final, kg & 30,8 & 29,2 & 29,4 & 29,9 & 0,68 & 0,35 \\
\hline GDM, g & 226,1 & 216,3 & 217,9 & 224,0 & 10,5 & 0,89 \\
\hline \multicolumn{7}{|l|}{ Consumo de MS } \\
\hline g/dia & 960,0 & 827,5 & 880,0 & 888,8 & 34,0 & 0,08 \\
\hline$\% \mathrm{PV}$ & 4,0 & 3,6 & 3,8 & 3,8 & 0,1 & 0,11 \\
\hline $\mathrm{g} / \mathrm{kg} \mathrm{PV}^{0,75}$ & 87,8 & 78,2 & 82,8 & 83,1 & 2,5 & 0,10 \\
\hline Consumo de $\mathrm{MO}$, g/dia & 716,6 & 640,9 & 689,3 & 688,2 & 27,1 & 0,29 \\
\hline $\mathrm{CPB}, \mathrm{g} / \mathrm{dia}$ & $151,7^{\mathrm{a}}$ & $104,3^{\mathrm{b}}$ & $107,8^{\mathrm{b}}$ & $112,3^{b}$ & 4,9 & $<0,01$ \\
\hline CFDN, g/dia & $228,2^{b}$ & $347,2^{\mathrm{a}}$ & $391,2^{\mathrm{a}}$ & $397,6^{\mathrm{a}}$ & 14,2 & $<0,01$ \\
\hline Eficiência alimentar & $0,235^{\mathrm{b}}$ & $0,265^{\mathrm{a}}$ & $0,248^{\mathrm{ab}}$ & $0,253^{\mathrm{ab}}$ & 0,01 & 0,03 \\
\hline
\end{tabular}

a,b Médias seguidas de letras distintas na mesma linha diferem $(\mathrm{P}<0,05)$ pelo teste Tukey.

${ }^{\mathrm{c}} \mathrm{GDM}$ = ganho diário médio; $\mathrm{MS}=$ matéria seca; $\mathrm{PV}=$ peso vivo; $\mathrm{PV}^{0,75}=$ peso metabólico; $\mathrm{MO}=$ matéria orgânica; $\mathrm{CMO}=\mathrm{consumo}$ de matéria orgânica; $\mathrm{CPB}=$ consumo de proteína bruta; CFDN = consumo de fibra em detergente neutro; eficiência alimentar = g de GDM/consumo de MS .

d Tratamentos: PCD = polpa cítrica desidratada; PCUD = 30\% de substituição da polpa cítrica peletizada pela polpa úmida semidespectinada; PCUDS = 30\% de substituição da polpa cítrica peletizada pela polpa úmida semidespectinada ensilada; PCUDS+B = 30\% de substituição da polpa cítrica peletizada pela polpa úmida semidespectinada ensilada com a adição de benzoato de sódio.

e EPM = erro-padrão da média.

${ }^{\mathrm{f}}$ Efeito $=$ valor de $\mathrm{P}$ para efeito de tratamento. 
Esses resultados corroboram os obtidos por Sarturi (2008) em pesquisa com bovinos alimentados com PCD e PCUD em rações contendo 15\% de cana-de-açúcar in natura e 85\% de concentrado. Da mesma forma, Pereira et al. (2007) avaliaram a utilização de polpa cítrica úmida prensada em substituição à silagem de milho em 0, 25, 50 e 75\% da MS sobre o peso vivo de abate e rendimento de carcaça quente utilizando cordeiros confinados e não verificaram efeito dos tratamentos sobre as variáveis. Esses resultados sugerem teor energético semelhante entre os subprodutos avaliados neste estudo, justificado pelo desempenho similar apresentado pelos animais no período de confinamento.

Os valores médios verificados para peso ao abate (PA), rendimento de carcaça quente (RCQ), perda por resfriamento (PR), área de olho-de-lombo (AOL) e espessura de gordura (EG) foram: 36,5 kg; 48,9\%; 3,7\%, 13,4 $\mathrm{cm}^{2}$ e 1,68 mm, respectivamente. Rodrigues et al. (2008b), avaliando esses parâmetros na carcaça de cordeiros alimentados com ração contendo 68,4\% de PCD, verificaram valores de 32,5 kg;
49,8\%; 2,9\%, $12,7 \mathrm{~cm}^{2}$ e $1,5 \mathrm{~mm}$, respectivamente. Caparra et al. (2007) encontraram valores menores para PA (28,8 kg) e PR (2,0\%) e similar para RCQ (48,7\%) quando avaliaram as características de carcaça de cordeiros recebendo $45 \%$ de polpa cítrica desidratada ao sol. Pereira et al. (2007) encontraram 44,7\% de RCQ para cordeiros Santa Inês abatidos com 32,7 kg alimentados com 45\% de polpa cítrica úmida prensada. A diferença de valores em relação aos reportados na literatura, que também utilizaram cordeiros alimentados com subprodutos da indústria citrícola, provavelmente pode ser justificada pelo maior peso ao abate deste estudo em comparação aos outros trabalhos.

No experimento 2 , não foi verificado efeito $(\mathrm{P}>0,05) \mathrm{da}$ adição de PCUD in natura ou na forma ensilada sobre os coeficientes de digestibilidade de MS, MO e PB entre as rações experimentais (Tabela 5), o que explica os resultados semelhantes de GDM e CMS no experimento de desempenho. Entretanto, a digestibilidade da FDN da ração contendo PCUD foi superior $(\mathrm{P}<0,05)$ à da $\mathrm{PCD}$, o que pode estar

Tabela 4 - Parâmetros de carcaça de cordeiros Santa Inês alimentados com polpa úmida semidespectinada in natura, ensilada com ou sem benzoato em substituição parcial a polpa cítrica desidratada

\begin{tabular}{lcccrr}
\hline Variáveis $^{\mathrm{a}}$ & \multicolumn{2}{c}{ Tratamento $^{\mathrm{b}}$} & EPM $^{\mathrm{c}}$ \\
\cline { 2 - 5 } & PCD & PCUD & PCUDS & PCUDS+B & \\
\hline Idade ao abate & 149 & 151 & 146 & 153 & 1,30 \\
Peso ao abate, kg & 36,6 & 35,8 & 36,8 & 36,6 & 0,37 \\
PCQ, kg & 18,1 & 17,6 & 17,7 & 17,9 & 0,47 \\
PCF, kg & 17,4 & 17,0 & 17,1 & 17,2 & 0,23 \\
RCQ, \% & 49,6 & 49,1 & 48,2 & 48,9 & 0,43 \\
RCF, \% & 47,8 & 47,3 & 46,5 & 47,1 & 0,45 \\
PR, \% & 3,6 & 3,9 & 3,6 & 3,7 & 0,43 \\
AOL, cm & 13,5 & 13,7 & 12,6 & 13,8 & 0,14 \\
EG, mm & 1,6 & 1,7 & 1,8 & 1,6 & 0,18 \\
\end{tabular}

a PCQ = peso de carcaça quente; PCF = peso de carcaça resfriada; RCQ = rendimento de carcaça quente; RCF = rendimento de carcaça fria; PR = perda por resfriamento; AOL = área de olho-de-lombo; EG = espessura de gordura.

b Tratamentos: PCD = polpa cítrica desidratada; PCUD = 30\% de substituição da polpa cítrica peletizada pela polpa úmida semidespectinada; PCUDS = 30\% de substituição da polpa cítrica peletizada pela polpa úmida semidespectinada ensilada; PCUDS+B = 30\% de substituição da polpa cítrica peletizada pela polpa úmida semidespectinada ensilada com a adição de benzoato de sódio.

' $\mathrm{EPM}=$ erro-padrão da média.

${ }^{\mathrm{d}} \mathrm{P}=$ valor de $\mathrm{P}$ para efeito de tratamento.

Tabela 5 - Digestibilidade dos nutrientes de rações contendo polpa úmida semidespectinada in natura, ensilada com ou sem benzoato em substituição parcial a polpa cítrica desidratada fornecidas para cordeiros

\begin{tabular}{|c|c|c|c|c|c|c|}
\hline \multirow[t]{2}{*}{ Variávelc } & \multicolumn{4}{|c|}{ Tratamento } & \multirow[t]{2}{*}{$\mathrm{EPM}^{\mathrm{e}}$} & \multirow[t]{2}{*}{$\mathrm{P}^{\mathrm{f}}$} \\
\hline & PCD & PCUD & PCUDS & PCUDS+B & & \\
\hline \multicolumn{7}{|c|}{ DATT, \% MS } \\
\hline MS & 79,7 & 80,8 & 78,5 & 76,0 & 0,87 & 0,13 \\
\hline MO & 82,9 & 83,7 & 81,1 & 78,7 & 0,77 & 0,07 \\
\hline PB & 68,5 & 73,0 & 73,3 & 72,2 & 2,10 & 0,60 \\
\hline FDN & $73,3 b$ & $82,7 \mathrm{a}$ & $76,7 \mathrm{ab}$ & $75,2 \mathrm{ab}$ & 1,65 & $<0,05$ \\
\hline
\end{tabular}

a,b Médias seguidas de letras distintas na mesma linha diferem $(\mathrm{P}<0,05)$ pelo teste Tukey.

c DATT = digestibilidade aparente no trato digestório total; MS = matéria seca; MO = matéria orgânica; FDN = fibra em detergente neutro; PB = proteína bruta.

d Tratamentos: PCD = polpa cítrica desidratada; PCUD $=30 \%$ de substituição da polpa cítrica peletizada pela polpa úmida semidespectinada; PCUDS = 30\% de substituição da polpa cítrica peletizada pela polpa úmida semidespectinada ensilada; PCUDS+B = 30\% de substituição da polpa cítrica peletizada pela polpa úmida semidespectinada ensilada com a adição de benzoato de sódio.

e EPM = erro-padrão da média.

${ }^{\mathrm{f}} \mathrm{P}=$ valor de $\mathrm{P}$ para efeito de tratamento. 
associado ao processo de extração de pectina, uma vez que o material é submetido ao tratamento com vapor à temperatura que varia entre 60 e $90^{\circ} \mathrm{C}$, dependendo do tipo de pectina que será produzida. Ao mesmo tempo, ocorre adição de ácido nítrico na massa até que o pH em solução no final do processo atinja aproximadamente 2,4 (Sarturi, 2008). Isso provavelmente deve ter alterado a composição física da porção fibrosa do co-produto, promovendo maior acessibilidade dos microrganismos ruminais à digestão da fibra.

Os coeficientes de digestibilidade da MS, MO e PB entre as silagens de PCUD e a PCUD in natura foram semelhantes $(\mathrm{P}>0,05)$, comprovando que o benzoato de sódio aplicado superficialmente à massa não alterou a composição química (Tabela 2) da silagem e que o subproduto possui características desejáveis para ser submetido ao processo de ensilagem.

Ítavo et al. (2000a) avaliaram silagem de bagaço de laranja, com ou sem aditivo enzimático microbiano e ácido fórmico ou acético na alimentação de cordeiros e não verificaram diferença entre os tratamentos para os coeficientes de digestibilidade dos nutrientes. Os valores encontrados para a digestibilidade da MS, MO, FDN e PB foram 82,7 a 90,1; 91 a 92,1; 67 a 71,2 e 69,2 a $71,1 \%$, respectivamente. As diferenças de valores entre os obtidos neste estudo e dos demais trabalhos podem ser atribuídas às divergências na composição do produto, devido à qualidade da laranja, à variedade, à região, à época do ano, à quantidade de sementes e aos processos industriais.

As concentrações de AGCC total, acetato, propionato, butirato e a relação acetato/propionato não foram alteradas $(\mathrm{P}>0,05)$, e não se verificou efeito de horas $(\mathrm{P}>0,05)$ e também de interação entre as rações experimentais e horas
( $\mathrm{P}>0,05)$ (Tabela 6). Conseqüentemente, o $\mathrm{pH}$ ruminal também não foi afetado pelos tratamentos $(\mathrm{P}>0,05)$. Entretanto, para esta variável verificou-se efeito de horas $(\mathrm{P}<0,01)$, não sendo verificada interação entre tratamentos e horas $(\mathrm{P}>0,05)$. Em conjunto, esses dados sugerem que apesar da menor concentração de pectina na PCUD (22\%) em relação à PCD (33\%), ambos os co-produtos apresentam padrão de fermentação ruminal semelhante. Seguramente, o aumento na digestibilidade da FDN com a utilização da PCUD na ração compensou parcialmente sua menor concentração de pectina. Estes resultados corroboram com os resultados de Ítavo et al. (2000b) avaliando o de bagaço de laranja aditivado com ácido fórmico e acético e aditivo enzimático microbiano na alimentação de cordeiros em rações contendo $70 \%$ de feno de aveia e $30 \%$ de bagaço de laranja.

A variação temporal do $\mathrm{pH}$ ruminal está apresentado na Figura 1, e o comportamento semelhante entre os tratamentos $(\mathrm{P}>0,05)$ reafirma a idéia de que os co-produtos avaliados apresentam padrão de fermentação ruminal semelhantes e que a adição de benzoato na silagem não promove alteração no seu metabolismo ruminal.

Os menores valores de $\mathrm{pH}$ ocorreram entre 2 e 4 horas após a alimentação e isso sugere rápida degradação dos subprodutos avaliados (Figura 1), justificando os altos valores de digestibilidade.

Apesar da redução de $\mathrm{pH}$ nesses horários, pode-se considerar que há estabilização do ambiente ruminal ao decorrer das 12 horas avaliadas, sendo justificado pelo fato da maior proporção dos AGCC produzidos no rúmen ser o acetato (Tabela 6). O acetato é reconhecidamente menos eficiente em reduzir o $\mathrm{pH}$ ruminal (Van Soest, 1994). Os valores de pH estão de acordo com Rihani et al. (1993), os

Tabela 6 - Parâmetros ruminais de cordeiros Santa Inês alimentados com polpa úmida semidespectinada in natura, ensilada com ou sem benzoato em substituição parcial a polpa cítrica desidratada

\begin{tabular}{|c|c|c|c|c|c|c|c|c|}
\hline \multirow[t]{2}{*}{ Variável ${ }^{\mathrm{C}}$} & \multicolumn{4}{|c|}{ Tratamento $^{\mathrm{d}}$} & \multirow[t]{2}{*}{$\mathrm{EPM}^{\mathrm{e}}$} & \multirow[t]{2}{*}{ Efeito $^{\mathrm{f}}$} & \multirow[t]{2}{*}{$\mathrm{H}^{\mathrm{g}}$} & \multirow[t]{2}{*}{$\mathrm{T}^{*} \mathrm{H}^{\mathrm{h}}$} \\
\hline & PCD & PCUD & PCUDS & PCUDS+B & & & & \\
\hline AGCCtotal, mM & 74,7 & 74,1 & 71,2 & 61,2 & 4,2 & 0,20 & 0,99 & 0,68 \\
\hline Acetato, mM & 56,8 & 55,6 & 54,7 & 48,9 & 2,7 & 0,29 & 0,99 & 0,72 \\
\hline Propionato, mM & 9,6 & 10,2 & 8,9 & 6,2 & 1,1 & 0,16 & 0,85 & 0,77 \\
\hline Butirato, mM & 7,2 & 7,1 & 6,2 & 4,8 & 0,7 & 0,17 & 0,85 & 0,95 \\
\hline$A: P$ & 7,9 & 6,8 & 8,2 & 11,1 & 1,5 & 0,35 & 0,96 & 0,65 \\
\hline $\mathrm{pH}$ & 6,7 & 6,4 & 6,6 & 6,5 & 0,1 & 0,47 & $<0,01$ & 0,63 \\
\hline $\mathrm{NH}_{3}, \mathrm{mg} / \mathrm{dL}$ & $4,6^{\mathrm{a}}$ & $3,4 \mathrm{ab}$ & $2,4 \mathrm{~b}$ & $2,5 b$ & 0,4 & 0,01 & 0,04 & 0,19 \\
\hline
\end{tabular}

a,b Médias seguidas de letras distintas na mesma linha diferem $(\mathrm{P}<0,01)$ pelo teste Tukey.

c AGCC = ácidos graxos de cadeia curta; $\mathrm{mM}=$ milimol; $\mathrm{A}: \mathrm{P}=$ relação acetato/propionato

d Tratamentos: PCD = polpa cítrica desidratada; PCUD = 30\% de substituição da polpa cítrica peletizada pela polpa úmida semidespectinada; PCUDS = 30\% de substituição da polpa cítrica peletizada pela polpa úmida semidespectinada ensilada; PCUDS+B = 30\% de substituição da polpa cítrica peletizada pela polpa úmida semidespectinada ensilada com a adição de benzoato de sódio.

e EPM = erro-padrão da média.

${ }^{\mathrm{f}}$ Efeito = valor de P para efeito de tratamento.

${ }^{8} \mathrm{H}=$ efeito de horas.

$\mathrm{h} \mathrm{T} * \mathrm{H}=$ efeito da interação entre tratamentos e hora. 


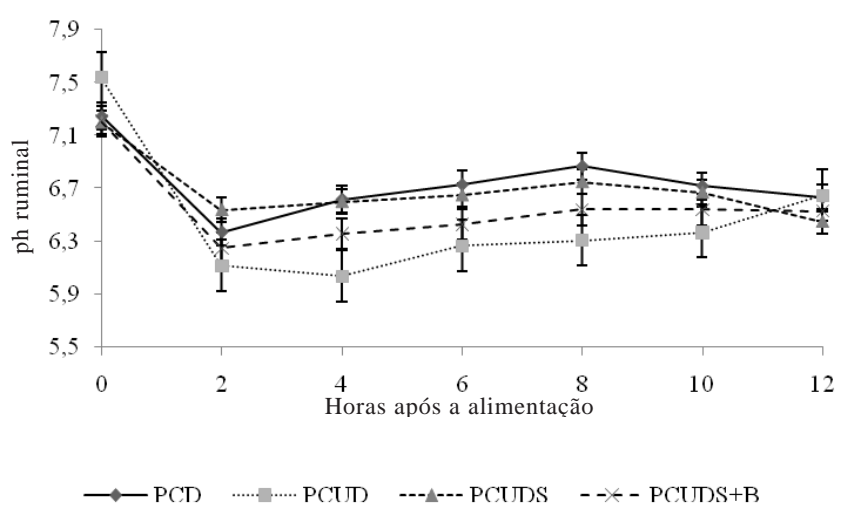

Figura 1 - pH do fluido ruminal de cordeiros Santa Inês em função da inclusão de PCUD, PCUDS e PCUDS+B nas rações em substituição parcial a PCD e das horas após a alimentação.

quais estudaram a utilização de bagaço de laranja desidratado e peletizado, em dietas isonitrogenadas, com ovinos em restrição de $80 \%$ do consumo voluntário. Os resultados do presente estudo evidenciam o quanto a polpa de citros em todas suas formas avaliadas é eficiente em manter o $\mathrm{pH}$ ruminal para adequada digestibilidade da fração fibrosa das rações, visto que mesmo se tratando de rações com alto teor de concentrado, em todos os horários avaliados o pH ruminal nunca foi inferior a 6,04. Esta constatação reforça a possibilidade da utilização destes co-produtos como ferramenta para formulação de rações de alto concentrado para cordeiros, reduzindo-se os riscos de ocorrência de distúrbios ruminais.

A concentração ruminal de nitrogênio amoniacal foi reduzida $(\mathrm{P}<0,01)$ nas rações contendo PCUD na forma de silagens em relação à PCD e a PCUD in natura. Adicionalmente, para esta variável verificou-se efeito $(\mathrm{P}<0,05)$ de horas após fornecimento das rações, não havendo interação entre tratamentos e horas $(\mathrm{P}>0,05)$.
A concentração média de $\mathrm{N}$ amoniacal (3,2 mg/dL) no fluido ruminal do presente estudo (Tabela 6) foi inferior ao observado por Ítavo et al. (2000b) que verificaram valor de $6,8 \mathrm{mg} / \mathrm{dL}$. Existe grande controvérsia em relação à concentração de $\mathrm{N}$ amoniacal ruminal exigida para o máximo crescimento microbiano. A menor concentração obtida nesse estudo (Tabela 6) foi 2,4 mg N/dL, valor abaixo dos citados por Satter \& Slyter (1974) e Mehrez et al. (1977), os quais afirmaram que o máximo de atividade fermentativa ruminal foi obtido quando o $\mathrm{N}$ amoniacal alcançou valores entre 5 e $23 \mathrm{mg}$ N/dL de líquido ruminal. Considerando a maior concentração de $\mathrm{N}$ amoniacal para o tratamento PCD em relação à PCUDS e PCUDS+B, era esperado melhor desempenho dos animais recebendo PCD em consequência de uma possível maximização do crescimento microbiano ruminal, o que não foi observado nesse estudo. Possivelmente, a menor degradação ruminal nas rações contendo as silagens pode ter sido compensada por uma maior passagem de proteína para o intestino delgado igualando o total de proteína metabolizável entre as rações. Além disso, a redução da degradabilidade ruminal da proteína bruta das rações contendo as silagens pode ter sido compensada por uma maior digestibilidade intestinal, uma vez que a digestibilidade no trato digestório total não foi alterada.

O consumo e a excreção de nitrogênio nas fezes e na urina não foi alterada $(\mathrm{P}>0,05)$ pelos tratamentos, consequentemente, não houve efeito $(\mathrm{P}>0,05)$ dos tratamentos sobre a retenção de $\mathrm{N}$ (Tabela 7). Estes resultados estão de acordo com os reportados na literatura com a utilização de polpa cítrica em substituição ao milho em rações para ruminantes (Esteves et al., 1987; Bueno et al., 2002; Rodrigues et al., 2008a). Por outro lado, os resultados observados por Henrique et al. (2003) mostraram melhor aproveitamento do nitrogênio em ovinos recebendo polpa cítrica, justificado pelo aumento da ingestão de MS com a

Tabela 7- Consumo e balanço de nitrogênio de cordeiros Santa Inês alimentados com polpa úmida semidespectinada in natura, ensilada com ou sem benzoato em substituição parcial à polpa cítrica desidratada

\begin{tabular}{|c|c|c|c|c|c|c|}
\hline \multirow[t]{2}{*}{ Variável } & \multicolumn{4}{|c|}{ Tratamento $^{\text {a }}$} & \multirow[t]{2}{*}{$\mathrm{EPM}^{\mathrm{b}}$} & \multirow[t]{2}{*}{$\mathrm{P}^{\mathrm{C}}$} \\
\hline & PCD & PCUD & PCUDS & PCUDS+B & & \\
\hline Consumo de N (g/dia) & 19,60 & 18,09 & 20,52 & 19,98 & 2,09 & 0,82 \\
\hline $\mathrm{N}$ nas fezes (g/dia) & 5,83 & 4,75 & 5,28 & 5,45 & 0,33 & 0,20 \\
\hline $\mathrm{N}$ na urina (g/dia) & 4,07 & 3,03 & 3,52 & 3,97 & 1,02 & 0,85 \\
\hline \multicolumn{7}{|l|}{$\mathrm{N}$ retido } \\
\hline g/dia & 9,69 & 10,31 & 11,71 & 10,56 & 2,62 & 0,93 \\
\hline$\%$ do $\mathrm{N}$ consumido & 48,46 & 55,49 & 56,11 & 53,53 & 7,85 & 0,86 \\
\hline$\%$ do $\mathrm{N}$ digerido & 70,18 & 76,26 & 76,78 & 74,79 & 9,00 & 0,93 \\
\hline
\end{tabular}


adição de PC. Alguns trabalhos ainda demonstraram redução no nitrogênio retido como o aumento da participação da polpa cítrica na ração (Bhattacharya \& Harb, 1973; Pascual \& Carmona, 1980). Apesar da divergência entre os trabalhos, a ausência de efeito sobre o metabolismo de nitrogênio neste estudo somente enfatiza a boa capacidade da PCUD ser armazenada em forma de silagem, além de substituir parcialmente a PCD.

\section{Conclusões}

A polpa cítrica úmida semidespectinada (PCUD), in natura ou na forma de silagens, pode ser usada em substituição a 30\% (em base de MS) da polpa cítrica peletizada, sem prejuízos ao desempenho, digestibilidade aparente da MS, fermentação ruminal e balanço de nitrogênio de ovinos alimentados com rações contendo alto teor de concentrado. Entretanto, a digestibilidade da FDN aumentou com a utilização da PCUD. Esses resultados sugerem que o uso parcial da polpa cítrica úmida semidespectinada in natura ou ensilada pode ser um ingrediente alternativo para cordeiros alimentados com rações contendo grande proporção de concentrado.

\section{Agradecimentos}

À CP-Kelco S.A. (Limeira, SP), pelo financiamento parcial deste trabalho.

\section{Referências}

ASSOCIATION OF OFFICIAL ANALYTICAL CHEMISTS - AOAC. Official methods of analysis. 15.ed. Washington, D.C.: 1990. 1298p.

BHATTACHARYA, A.N.; HARB, M. Dried citrus pulp as grain replacement for Awassi lambs. Journal of Animal Science, v.36, n.6, p.1175-1180, 1973.

BRASIL. Ministério da Agricultura. Decreto lei n. 2.244, 5 jun., 1997. Regulamento da inspeção industrial e sanitária de produtos de origem animal. Brasília, 1997. 204p.

BUENO, M.S.; FERRARI E.; BIANCHINI, D. et al. Effect of replacing corn with dehydrated citrus pulp in diets of growing kids. Small Ruminant Research, v.46, n.2-3 p.179-185, 2002.

CAMPOS, F.P.; NUSSIO, C.M.B.; NUSSIO, L.G. Métodos de análises de alimentos. Piracicaba: FEALQ, 2004. 135p.

CAPARRA, P.; FOTI, F.; SCERRA, M. et al. Solar-dried citrus pulp as an alternative energy source in lamb diets: effects on growth an carcass and meat quality. Small Ruminant Research, v.40, n.3, p.303-311, 2007.

CHANEY, A.L.; MARBACH, E.P. Modified reagents for determination of urea and ammonia. Clinical Chemistry, v.8, n.2, p.130-137, 1962.

ESTEVES, S.N.; MANZANO, A.; NOVAES, N.J. et al. Substituição da espiga de milho desintegrada com palha e sabugo pela polpa de citros peletizada na engorda de bovinos Canchim. Revista da Sociedade Brasileira de Zootecnia, v.16, n.6, p.507-516, 1987.
HENRIQUE, W.; SAMPAIO, A.A.M.; LEME, P.R. et al. Digestibilidade e balanço de nitrogênio em ovinos alimentados à base de dietas com elevado teor de concentrado e níveis crescentes de polpa cítrica peletizada. Revista Brasileira de Zootecnia, v.32, n.6, supl.2, p.2007-2015, 2003.

HOLDEN, L.A. Comparison of methods of in vitro dry matter digestibility for ten feeds. Journal of Dairy Science, v.82, n.8, p.1791-1794, 1999.

ÍTAVO, L.C.V.; SANTOS, G.T.; JOBIM, C.C. et al. Composição e digestibilidade aparente da silagem de bagaço de laranja. Revista Brasileira de Zootecnia, v.29, n.5, p.1485-1490, 2000a.

ÍTAVO, L.C.V.; SANTOS, G.T.; JOBIM, C.C. et al. Avaliação da silagem de bagaço de laranja com diferentes aditivos por intermédio dos parâmetros de fermentação ruminal de ovinos e contribuição energética dos ácidos graxos voláteis. Revista Brasileira de Zootecnia, v.29, n.5, p.1491-1497, 2000b.

LEONARDI, C.; GIANNICO, F.; ARMENTANO, L.E. Effect of water addition on selective consumption (sorting) of dry diets by dairy cattle. Journal of Dairy Science, v.88, p.1043-1049, 2005.

MEHREZ, A.Z.; ØRSKOV, E.R.; McDONALD, I. Rates of rumen fermentation in relation to ammonia concentration. British Journal of Nutrition, v.38, n.3, p.437-443, 1977.

MERTENS, D.R. Análise da fibra e sua utilização na avaliação de alimentos e formulação de rações. In: SIMPÓSIO INTERNACIONAL DE RUMINANTES, REUNIÃO ANUAL DA SOCIEDADE BRASILEIRA DE ZOOTECNIA, 29., 1992, Lavras. Anais... Lavras: SBZ, 1992. p.188-219.

PALMQUIST, D.; CONRAD, H. Origin of plasma fatty acids in lactating cows fed high fat diets. Journal of Dairy Science, v.54, n.7, p.1025-1033, 1971.

PASCUAL, J.M.; CARMONA, J.F. Composition of citrus pulp. Animal Feed Science and Technology, v.5, n.1, p.1-10, 1980.

PEREIRA, M.S.; RIBEIRO, E.L.A.; MIZUBUTI, I.Y. et al. Carcaça e não-componentes da carcaça de cordeiros recebendo polpa cítrica úmida prensada em substituição à silagem de milho. Acta Scientarium Animal Science, v.29, n.1, p.57-562, 2007.

QUEIROZ, M.A.A.; SUSIN, I.; PIRES, A.V. et al. Desempenho de cordeiros e estimativa da digestibilidade do amido de dietas com diferentes fontes protéicas. Pesquisa Agropecuária Brasileira, v.43, n.9, p.1193-1200, 2008.

RIHANI, N.; GARRET, W.N.; ZINN, R.A. Effect of source of supplemental nitrogen on the utilization of citrus pulp-based diets by sheep. Journal of Animal Science, v.71, n.9, p.23102321, 1993.

RODRIGUES, G.H.; SUSIN, I.; PIRES, A.V. et al. Substituição do milho por polpa cítrica em rações com alta proporção de concentrado para cordeiros confinados. Ciência Rural, v.38, n.3, p.789-794, 2008a.

RODRIGUES, G.H.; SUSIN, I.; PIRES, A.V. et al. Polpa cítrica em rações para cordeiros em confinamento: características da carcaça e qualidade da carne. Revista Brasileira de Zootecnia, v.37, n.10, p.1869-1875, 2008b.

SARTURI, J.O. Polpa cítrica úmida despectinada em substituição à polpa peletizada no desempenho de bovinos de corte confinados. 2008. 132f. Dissertação (Mestrado em Ciência Animal e Pastagem) - Escola Superior de Agricultura "Luiz de Queiroz", Universidade de São Paulo, Piracicaba.

SATTER, L.D.; SLYTER, L.L. Effect of ammonia concentration on rumen microbial protein production in vitro. British Journal of Nutrition, v.32, n.2, p.199-208, 1974

STATISTICAL ANALYSIS SYSTEM - SAS. User's guide. Cary: SAS Institute, 2002. 525p.

URANO, F.S.; PIRES, A.V.; SUSIN, I. et al. Desempenho e características da carcaça de cordeiros confinados alimentados com grão de soja. Pesquisa Agropecuária Brasileira, v.41, n.10, p.1525-1530, 2006.

VAN SOEST, P.J. Nutritional ecology of the ruminant. 2.ed Ithaca: Cornell University Press, 1994. 476p 
VAN SOEST, P.J.; ROBERTSON, J.B.; LEWIS, B.A. Methods for dietary fiber, neutral detergent fiber, and non starch polysaccharides in relation to animal nutrition. Journal of Dairy Science, v.74, n.10, p.3583-3597, 1991.
WILES, P.G.; GRAY, I.K.; KISSLING, R.C. Routine analysis of proteins by Kjeldahl and Dumas methods: review and interlaboratory study using dairy products. Journal of AOAC International, v.81, n.3, p.620-632, 1998. 